\title{
EL VIZCONDE DEMEDIADO: UN CONFLICTO ENTRE EL BIEN Y EL MAL
}

\author{
Ma José Bonachía \\ Departamento de Filologias Modernas \\ Universidad de La Rioja
}

\begin{abstract}
RESUMEN: el presente estudio se centra en la obra de I. Calvino, El Vizconde Demediado, un relato fantástico de un hombre dividido en dos mitades contrapuestas entre sí.

En nuestro análisis demostramos cómo la reiterada presencia de la antítesis y otros recursos narrativos, sirven al autor para construir un universo dualista en el que el Bien y el Mal aparecen en perpetua confrontación.

De igual modo, señalamos la importancia que tiene para Calvino, la aspiración a la idea de plenitud, más allá de todas las mutilaciones que la sociedad impone.

RÉSUMÉ: cette étude est centrée sur l'oeuvre d'I. Calvino, El Vizconde Demediado, un récit fantastique d'un homme divisé en deux parties opposées.

Dans notre analyse nous montrons que l'auteur, se servant à plusieurs reprises, de l'antythèse et d'autres procédés narratifs, construit un univers dualiste où le Bien et le Mal apparaissent perpétuellement confrontés.

Nous signalons également que, ce qui compte pour l'auteur est l'aspiration à l'idée de plénitude, bien au-delà de toutes les mutilations imposées par la société.
\end{abstract}

La obra ${ }^{1}$ aparece estructurada sobre la idea de la unidad divisa, ya que el hombre está dividido, incompleto, mutilado. Se trata de una historia inverosímil y alegórica que se desarrolla en una época lejana en un país imaginario ${ }^{2}$, en espacios ficticios, en la que el personaje principal, el vizconde Medardo, aparece dividido en dos mitades contrapuestas, una buena y otra mala, que constituyen un reflejo del bien y del mal existente en cada uno de nosotros.

1. CALVINO, I., Il visconte dimezzato, Garzanti Editore, s.p.a, 1985. Las citas del texto remitirán a esta edición.

2. "A lo que no he querido renunciar es a la carga épica y de aventura, de energía física y moral, y puesto que las imágenes de la vida contemporánea no podían satisfacer mi deseo en este sentido, me ha parecido natural transferir esta carga en aventuras fantásticas, fuera de nuestro tiempo, fuera de la realidad..." CALVINO, I., Punto y aparte, ensayos sobre literatura y sociedad, Tusquets, Barcelona, 1995. p. 70. 
El texto tiene una estructura circular, dividida también en dos partes antitéticas. Se parte de una unidad, un personaje entero, que se escinde en dos mitades opuestas para volver otra vez, al final de la obra, al punto de partida, si bien la unidad resultante es más armónica que la inicial.

El tema de la obra reproduce la historia de un mito universal, el del "eterno retorno"3, por el que el Ser y el Cosmos permanecen eternamente siendo y no siendo, llegando a ser y dejando de ser, repitiéndose hasta lo infinito.

Los dos apectos, positivo y negativo, del personaje se conectan con otro mito clásico, el de la pareja de hermanos ${ }^{4}$ : Prometeo, el bienhechor de la humanidad y Epimeteo, su antítesis exacta, que se constituyen en una oposición de hermano bueno/hermano malo, causante este último de todas las desgracias.

Esta oposición nos introduce también en el tema del doble, entendido desde el planteamiento de dos entidades psicológicas antagónicas, que representan la parte positiva y negativa de la personalidad, según la consideración psicoanálitica de Jung y su escuela.

Por lo tanto, nuestro estudio va a ir encaminado a analizar, en primer lugar, la trayectoria del personaje principal en cada una de sus dos mitades: la negativa o del Doliente y la positiva, del Bueno; en segundo lugar, la del resto de los personajes que completan el significado de la mutilación del vizconde desde otros ángulos. Para ello nos apoyaremos en los numerosos elementos simbólicos, imágenes, reflejos y correspondencias de un texto polisémico, que van a aclarar el mensaje del autor. Por último, analizaremos algunos de los recursos narrativos más significativos utilizados.

\section{El doliente}

El nombre del protagonista de la obra es Medardo $^{5}$ de Terralba en clara referencia a la naturaleza demediada del personaje; sin embargo nadie llamará al vizconde por su nombre, pues son otros los nombres que lo definen: El Doliente, El Manco, El Tuerto, El Roto, El Cojo, El Desnalgado, El Medio Sordo, El Sutil; es decir, apelaciones que lo identifican y que se asocian significativamente con su mitad negativa en imágenes de mutilación, destrucción y muerte.

En un primer tiempo sobrevive la parte negativa del personaje, la que, en terminología junguiana, podemos denominar "la sombra"6, es decir, el doble negativo.

3. Vid. ELIADE, M., El mito del eterno retorno, Alianza/Emecé, Madrid, 1982.

4. Vid. GRIMAL, P., Diccionario de mitología griega y romana, Paidós, Barcelona, 1994, arts. "Prometeo "y "Epimeteo".

5. El juego de nombres utilizado en los distintos momentos del relato contribuye a dar un tono inquietante y misterioso, a la vez que una gran expresividad en lo que significan; se hace patente el poder evocador de la etimología y del simbolismo de los mismos.

6. VON FRANZ, M-L., en su obra L'ombre et le mal dans les contes de fées, señala que, según una ley general, la sombra sería lo que no queremos conocer de nosotros mismos, lo que no queremos vivir de 
Curiosamente se trata de la parte derecha, quizá como un contraste más dentro de los muchos que aparecen a lo largo de la novela, pues en la simbología tradicional, o más bien, en la cultura occidental judeo-cristiana, el hemisferio derecho, y la derecha ${ }^{7}$ se consideran positivos en contraposición a la izquierda, y aquí se presentan a la inversa.

Su propio aspecto físico es inquietante y fantasmagórico:

"Che questo corpo non ci fosse affatto, e il mantello fosse vuoto come quello d'un fantasma” (p. 20).

y va unido al color negro ${ }^{8}$ de su manto, a la sombra negra que produce su perfil, a los gestos ásperos, a su gélida sonrisa triangular, a su piel tensa como una calavera, a su sonrisa hierática, a su esfuerzo anguloso y convulso cuando se mueve, a su ojo de rapaz, etc.

Hemos hecho alusión a su "ojo de rapaz", y es que el vizconde Medardo, al estar demediado, ha perdido una parte de su sustancia corpórea, apareciendo por ello "descarnado" y con ciertos rasgos de naturaleza etérea, pues posee movimientos aerodinámicos, como las aves.

Rousseau ${ }^{9}$ asocia el color negro, en lo que éste significa de cambio de estado, con los pájaros, que representan el devenir, la unión del presente y el futuro:

"E così il visconte cavalcava con in testa un cappello piumato a larghe tese, che per metà scompariva sotto un'ala del mantello sempre svolazzante" (p. 33).

Por su parte G. Bonaviri10 hace referencia a "l'oisellité" de Calvino no sólo por su aspecto físico, que le recuerda a un milano, sino también por su estilo literario, que le hace semejante a diferentes ritmos y movimientos de ese pájaro. En efecto, en el texto aparecen numerosas referencias al universo de los pájaros y a la imaginaria del ala, que nada tienen que ver con los valores sublimes de ascensión y perfección que G. Bachelard11 les atribuye.

En el texto, antes de la batalla, el ala aparece ligada a aves depredadoras, cuer$\operatorname{vos}^{12}$ y buitres, así como a otras aves rapaces, que anuncian la muerte. Pero además,

manera consciente y que se convierte en una especie de segunda personalidad más o menos disociada y autónoma.

7. Así p.e., la mano derecha, por su asimiliación a la diestra de Dios, representa la "mano de la justicia" y otros valores morales positivos.

8. Aquí el color negro evoca la parte oscura y demoníaca del personaje.

9. ROUSSEAU, R.L., Le langage des couleurs, Ed. Dangles, St. Jean de Braye, 1980, pp.149-150.

10. BONAVIRI, G., "L'oiseau littéraire" en Magazine littéraire, n 274, Février, 1990. pp. 23-24.

11. "La force de l'aile est par nature de pouvoir élever et conduire ce qui est pesant vers les hauteurs où habite la race des dieux” BACHELARD, G., L'air et les songes, J. Corti, Paris, 1978, p. 82.

12. VON FRANZ, M.L., corrobora esta idea en su obra La voie de l'individuation dans les Contes de Fées, señalando que, en la mitología, estos pájaros están asociados de manera especial al poder de adivinación, a la "seconde vue". 
el ala negra de estos mismos pájaros es, al mismo tiempo, augurio y representación de la decadencia moral y física que se avecina en la persona del vizconde.

También en el campo de batalla hay cuerpos inexplicablemente emplumados donde, por un efecto de extraña metamorfosis, se confunden el hombre y el pájaro.

"Come se da quelle loro macilente braccia e costole fossero cresciute nere penne e ali “ (p. 8).

Del mismo modo, el vizconde Aiolfo, padre de Medardo, tiene una pasión desmedida por los pájaros, aunque éstos aparezcan en cautividad. Esperando la vuelta de su hijo, no sale ni de noche ni de día de su habitación, en la que está encerrado con una gran pajarera, donde además de otros pájaros, hay faisanes y tórtolas. Y así, uno de los animales más queridos del viejo vizconde es un alcaudón que él ha amaestrado para que vuele hasta el ala de los aposentos de Medardo, tratando de calmar el dolor de su hijo cuando regrese de la guerra.

"Quel matino il vecchio aperse lo sportello all'averla, ne seguì il volo fino alla finestra del figlio, poi tornò a spargere il becchime alle gazze e alle cince, imitando i loro zirli “ (p. 22).

El alcaudón, como los otros pájaros ${ }^{13}$ que aparecen junto al vizconde Aiolfo, mientras éste está con vida, representan un proceso de realización, de integración, son mensajeros de amor humano. Sin embargo, con la muerte del vizconde, se quebrarán también los atributos del ala, pues las aves que habían estado revoloteando en torno a su lecho de muerte ya no quieren volar:

"Da quando s'era coricato avevano preso tutti a svolazzare e non volevano posarsi né smettere di battere le ali.

La mattina dopo, la balia, affacciandosi all'ucccelliera, vide che il visconte Aiolfo era morto. Gli uccelli erano tutti posati sul suo letto" (p. 23).

En el texto, la simbología de los pájaros, del ala y del vuelo, adoptan un movimiento progresivo, paralelo al del personaje Medardo, comparable él mismo a un pájaro de mal agüero; las aves aparecen primero como signos de muerte, luego en cautividad y por fin tullidas, como una imagen duplicada del vizconde. En todos los casos, las aves, depredadoras o mensajeras, lejos de evocar el dinamismo de las alturas y la libertad del mundo, son aves terrestres, asociadas a la constricción y a las limitaciones del ser humano.

13. Vid. VON FRANZ, La voie de l'individuation dans les contes de fées, La Fontaine de Pierre, Paris, 1978, Cap. Le symbolisme de l'oiseau. 
"La balestra del visconte da tempo colpiva solo più le rondini; e in modo non da ucciderle ma solo da ferirle e da storpiarle. Però ora si cominciavano a vedere nel cielo rondini con le zampine fasciate o con le ali incollate o incerottate; c'era tutto uno stormo di rondini così bardate che volavano con prudenza tutte assieme, come convalescenti d'un ospedale uccellesco, e inverosimilmente si diceva che lo stesso Medardo ne fosse il dottore" (p. 71).

Sin embargo, este aspecto de la volatilidad aparece más desarrollado en El Barón rampante, segunda obra de la trilogía, donde el protagonista, al vivir en los árboles, pertenece más al mundo etéreo de los pájaros con quienes convive, que al mundo terrestre.

Antes de comentar el comportamiento moral del vizconde, hemos de señalar que el relato está lleno de signos, de premoniciones ${ }^{14}$ y de correspondencias precursoras de acontecimientos futuros. Así, antes de la batalla de tan terribles consecuencias para el vizconde, se preconizan los males que se avecinan, "Se avese potuto prevedere la terribile sorte che l'attendeva.." (p. 12) y que van a ser causa de posteriores desdichas, con imágenes de dolor (enfermedad), destrucción (despojos), miseria (podredumbre) y muerte. Es una muerte total que afecta al hombre, al animal y a la naturaleza, y que en el campo de batalla constituye una verdadera plaga (aire opaco y quieto, campiña agotada por la carestía, sequía en los ríos, muerte del hombre y del pájaro, peste exterminadora, cuerpos desfigurados, cadáveres de hombres y mujeres, cadáveres de buitres, cadáveres equinos, tajo de cimitarras turcas, cuerpos enterrados, miembros sueltos, nubes de moscas, montañas de excrementos...).

Según M. Eliade15, las guerras, las destrucciones, los sufrimientos históricos no son ya los "signos precursores" del paso de una edad cósmica a otra, sino que constituyen por sí mismos ese pasaje.

El regreso del vizconde a Terralba después del trágico accidente está precedido igualmente de signos de índole negativa: la atmósfera externa: la noche, el mar gris, la oscuridad, el cielo cubierto, la ruina de muros y torres del castillo familiar, padre encerrado, rejas en la habitación... signos, todos ellos, que preconizan la muerte que se manifestará con su vuelta. Primero, la del alcaudón, después la de su padre y, por último, la de todo ser viviente.

Estos antecedentes preparan al lector para comprender en cierta forma la maldad del vizconde que, desde el primer momento, va a mostrar una gran crueldad con todos los seres vivientes: humanos, animales y plantas.

14. Pasado impreciso y mítico o actualizado bruscamente por anacronismos deliberados, futuro haciendo irrupción en el presente por medio de la premonición o profecía...Es de todas formas la negación del tiempo cronológico y de los acontecimientos. Juego sutil de correspondencias, de anuncios y recuerdos. Cf. Ribard, J., Le moyen âge, Littérature et symbolisme, H. Champion/Essais, Paris, 1984. p. 133.

15. ELIADE, M., Opus cit., p. 127. 
Aparecen señales evidentes de su furia al pretender que todo lo que le rodea se parezca a él, en una asimilación múltiple de identidad, provocando un efecto especular del personaje con un mundo a su imagen y semejanza.

Hemos aludido ya al alcaudón muerto y destrozado; después, el episodio de los hongos venenosos con los que el vizconde pretendía envenenar a su sobrino. En esta escena, que tiene lugar en el prado "de las monjas", el juego de reflejos del rostro del Doliente y de los hongos buenos flotando en el agua nos remiten al mito de Narciso; los contrastes de color blanco/negro y de luz/sombra que rodean la escena nos parecen muy significativos por la imbricación de símbolos, que se refuerzan unos a otros para señalar lo opuesto.

Más tarde será el decreto de muerte en la horca a Fiorfero y su banda de reos de rapiña y también los de caza furtiva. En otra ocasión, el autor describe el regocijo del vizconde al contemplar el trágico éxito de la trampa tendida a los aldeanos que fueron tragados a plomo por el torrente mientras chillaban de espanto. El terror también asaltó a los siervos, entre los campesinos crecía el odio contra él, todos se habían convencido ya de que su naturaleza estaba abocada a una "irreparable e insana crueldad". Por todas partes no se oía hablar más que de la furia demediadora del vizconde y del miedo que infundía a todo el mundo ${ }^{16}$.

"La cattiveria del visconte non risparmiava nessuno e poteva scatenarsi da un momento all'altro nelle azioni più impreviste e incomprensibili” (p. 33).

"Trelawney, Pietrochiodo, gli ugonotti, i lebbrosi, tutti eravamo sotto il segno dell'uomo dimezzato" (p. 51)

Sus acciones se asocian, pues, con la espada, la maldad, la crueldad, la mutilación, la condena a muerte, el patíbulo para inocentes, los cuerpos desgarrados, los instrumentos de tortura encargados al maestro Pietrochiodo:

"Ormai erano dei veri capolavori di falegnameria e di meccanica, e non solo le forche, ma anche i cavalletti, gli argani e gli altri strumenti di tortura con cui il visconte Medardo strappava le confessioni agli accusati” (p. 35).

Por otro lado, todas sus apariciones hay que asociarlas a la noche: su regreso a Terralba, sus salidas demediadoras, así como su encuentro con el doctor Trelawney, que se desarrolla una noche en el cementerio "mientras pasea haciendo pastar a su caballo entre las tumbas”.

16 Podemos interpretar estos actos del vizconde como un intento para librarse de su mal y transferirlo a los demás. Como señala FRAZER, J.G., La rama dorada, Fondo de Cultura Económica, S.A., Madrid, 1989, estas prácticas de transferencia a hombres, animales u objetos inanimados han sido muy frecuentes en todas las épocas tanto entre los pueblos bárbaros y salvajes como en los más civilizados. 
Otra de sus crueldades nocturnas se materializa en los incendios; quema los heniles, árboles o todo el bosque, incendiando los bienes y las viviendas; también una noche provoca un incendio con pez y fuego entre los leprosos de Pratofuengo. Su maldad se dirige incluso contra su propio castillo, en un atentado contra la vida de su nodriza y "vicemadre" Sebastiana, que bien puede interpretarse como un atentado contra la figura materna que simboliza el bien. Como la nodriza consigue salvarse, de nuevo una noche la visita para enviarla a Pratofuengo.

Por consiguiente, en este relato la noche no representa únicamente la oposición al día, sino que evoca y se asocia con el color negro, la muerte y la crueldad de todo tipo, como ya hemos apuntado.

La visita del vizconde a los hugonotes de Col Gerbido tiene lugar igualmente una noche "de perros", en unas circunstancias en las que se aúnan la cólera del viento, la tormenta y el rayo. Estas monstruosas imágenes de la tempestad constituyen una especie de espejismo sonoro que proyecta el espanto producido por el vizconde en el universo, pero significan también la cólera creadora, el torbellino cosmogónico.

"Fuori: tuoni e lampi e pioggia dirotta..- Diluvièra tutta notte..Eravamo zuppi e infangati.. Fuori sembrava che tutti i tuoni e i fulmini si scaricassero su Col Gerbido" (p. 46).

"In quel momento una folgore squarciò il cielo, e il tuono fece tremare le tegole e le pietre delle mura" (p. 50).

En el transcurso de este encuentro, que precisamente, coincide con la mitad del relato, el viejo Ezequiel profetiza la visita de la mitad buena de Medardo.

La presencia del viejo nos traslada a un tiempo bíblico, ya que, por similitud, se puede hablar de un tiempo apocalíptico, el del Mal y el Caos (Doliente), que preludia a su vez la llegada de la Paz y del Bien (Mesías), pues estamos de nuevo ante un mito cosmogónico: Tras el Caos, la Armonía.

"Figli, era scritto che per primo venisse lo Zoppo, a visitarci... non disperate, figli: forse un giorno passerà un miglior viandante" (p. 49).

El roble, partido por la mitad como el vizconde, forma parte de la simbología mesiánica, es el roble sagrado, manifestación del rito cíclico de la naturaleza. La mitad del árbol carbonizado representa el sacrificio del Doliente para que pueda renacer la otra mitad, la del Bueno, tal como formalmente sucede en la obra a partir de este episodio.

"Il fulmine è caduto sulla rovere! Ora brucia!... Videro il grande albero carbonizzato per metà, dalla vetta alle radici, e l'altra metà era intatta" (p.50). 
Ma JOSÉ BONACHÍA

\section{El bueno}

Para nombrar la parte izquierda ${ }^{17}$ del personaje se recurre a apelaciones antonomásicas, así será llamado "El cojo de la otra pierna”, El Manco-Zurdo", "Un Simpié”, "El Destrozado", "El medio vizconde bueno",’Un medio hombre”.

La anunciada irrupción del Bueno, salvando de una picadura venenosa a su sobrino, se produce sin embargo de forma sorpresiva, cuando éste se despierta de un sueño mientras pescaba.

También Pamela se siente sorprendida por las bondades del Bueno un día de temporal y tormenta. Incluso esta circunstancia, que con el Doliente tenía un carácter tenebroso, se torna ahora positiva por las imágenes que la acompañan (gruta, refugio, la alegría de Pamela) y por la aparición del arcoiris en el cielo, como preludio de la armonía venidera y símbolo de esperanza de una nueva era. Y es que, contrariamente a lo sucedido con el Doliente, la llegada del Bueno está precedida de una trayectoria de hombre bueno y santo no exenta de connotaciones bíblicas, a las que ya estamos acostumbrados.

\footnotetext{
"Aveva percorso per mesi e anni le nazioni cristiane per tornare al suo castello, meravigliando le genti lungo la via coi suoi atti di bontà" (p. 73).
}

Lo mismo ocurre con su aspecto físico: aunque demediado también, se contrapone al de su otra mitad: "La mezza boca del visconte s' arcuava in un dolce, incompleto sorriso” (p. 74). Su expresión es dulce, está lleno de humanidad y cortesía y sus actos van a caracterizarse por la generosidad y la bondad con todos los seres vivientes.

"Passando di qui ho visto un'anguilla dibattersi presa all'amo e m'ha fatto tanta pena che l'ho liberata; poi pensando al danno che avevo col mio gesto arrecato al pescatore, ho voluto ripagarlo col mio anello, ultima cosa di valore che mi resta" (p. 66).

Su vestimenta humilde, como la de un vagabundo, "medio envuelto en un destrozado manto negro", "traje de fustán pelado y desteñido" y "calza de lana de listas azules y blancas, llena de remiendos", contrasta también con la capa negra, traje de terciopelo negro y alta bota de cuero del Doliente.

En un principio es considerado por todos como un santo, ya que sus actos están encaminados a ayudar y a socorrer en cuerpo y alma al que lo necesita, tanto personas como animales; representa la piedad y la caridad en su grado sumo, es decir, el otro extremo del Doliente.

17. "La gauche récele la part héréditaire et réceptive, le côté social et conformiste de l'individu". BENOIST, L., Signes, Symboles et mythes, PUF, Paris, 1975, p. 46. 
"Gli storpi, i poverelli, le donne tradite, tutti quelli che avevano una pena correvano da lui...E non c'era pecora che si spezzasse gamba in burrone, non bevitore che traesse coltello in taverna, non sposa adultera che corresse nottetempo ad amante, che non se lo vedessero apparire lì come piovuto dal cielo, nero e secco e col dolce sorriso, a soccorrere, a dar buoni consigli, a prevenire violenze e peccati" (p. 78).

Como ya hiciera el Doliente, y corroborando la profecía anunciada por el viejo Ezequiel,

"Padre nostro, Ezechiele, -dissero, - quando venne il Sottile, quella notte, e il fulmine incendiò mezza rovere, voi diceste che forse un giorno saremmo stati visitati da un viandante migliore" (p. 80).

el Bueno visita también a los hugonotes, pero con una actitud contraria a la del primero. Ahora, el personaje es la representación de la humildad, reflejada no sólo en su proceder, sino también en su vestimenta y en el mulo a lomos del cual sube el empinado camino de herradura al cerro de los hugonotes. La disposición del Bueno queda patente en la siguiente enumeración:

"Il Buono rispose cerimoniosamente a quei saluti, baciò la mano alla moglie di Ezechiele... s'informò della salute di tutti, allungò la mano...s'interessò ai fastidi di ciascuno, si fece raccontare la storia delle loro persecuzioni” (p. 82)

Sin embargo, los hugonotes le van a perder el respeto poco a poco ya que se dedica a espiarles y a arruinarles sus tratos, pues al cabo de un tiempo, su dedicación por la gente llegaba a tal extremo que nadie le soportaba, puesto que se entrometía en sus vidas y les daba lecciones de moral18. Tampoco los leprosos podían aguantarle al proponerse curar no sólo sus cuerpos sino tambien sus almas.

"Nostri sentimenti si facevano incolori e ottusi, poiché ci sentivamo come perduti tra malvagità e virtù ugualmente disumane" (p. 91).

Además, su extrema compasión tenía a veces resultados contrarios a los buscados: por ejemplo, los esbirros que quieren salvarle la vida son condenados al patíbulo

18. El yo "bueno" adopta una actitud moral rígida y por eso el conflicto entre ambas partes se agudizará, sin que la situación evolucione. Uno de los mayores problemas de nuestra civilización occidental es la compartimentación de los valores, del bien y del mal. En la civilización oriental, por el contrario, estos valores son relativos, se completan en lugar de oponerse. 
por seguir sus instrucciones; la muleta que regala al viejo Isidoro para caminar, es utilizada por éste para apalear a su mujer, etc.

Este comportamiento del personaje podemos explicarlo aplicando el principio de polaridad, de acuerdo con el Kybalión ${ }^{19}$, que dice lo siguiente:

"Todo es doble; todo tiene dos polos; todo, su par de opuestos: los semejantes y los antagónicos son lo mismo; los opuestos son idénticos en naturaleza, pero diferentes en grado; los extremos se tocan; todas las verdades son semiverdades; todas las paradojas pueden reconciliarse".

\section{Otros personajes}

Hemos señalado el demediamiento, tanto físico como psíquico, del vizconde y también el constante juego especular de reflejos que existen en el texto. De este modo, los personajes que rodean al vizconde ilustran y completan a su manera otros tipos de mutilación diferentes, si bien su comportamiento va a discurrir en paralelo al de cada una de las dos mitades del vizconde.

a) Pietrochiodo, el albardero, es un hombre de mucho talento, especializado en la construcción de los más ingeniosos y perfectos instrumentos de tortura, entre otros el "árbol de la muerte"20. Mientras trabaja para el Doliente no quiere pensar en el uso que se va a hacer de sus inventos, aunque se pregunte por ello repetidamente:

"Come faccio, - pensava, - a farmi dar da costruire qualcosa d'altrettanto ben congegnato, ma che abbia un diverso scopo? (p. 35)

b) El doctor Trelawney, por su parte, representa la inconsciencia; es una persona sabia a la que no le importa en modo alguno su profesión de médico sino que se dedica a investigar otras cosas. Está presentado como un hombre lleno de contrastes y paradojas, pues antes de llegar a Terralba había realizado viajes largos y peligrosos, pero nunca había visto nada del mundo, ya que siempre estaba bajo cubierta jugando a las cartas, y aunque ha pasado la vida en los barcos no sabe nadar, etc. En lugar de cuidar a los enfermos se dedica a sus descubrimientos científicos, a saber: investigar una extraña e imperceptible enfermedad de los grillos, estudiar los fósiles marinos y los fuegos fatuos que pesca con una red como si fueran mariposas y que luego coloca en distintos recipientes (sacos, alcollas, damajuanas sin paja, braserillos, coladores..) ${ }^{21}$.

19. TRIMEGISTO, H., Tres iniciados, El Kybalion, Edaf, México, 1983, p. 24.

20. La metáfora de la horca "ramificada como un árbol", atribuye a éste características opuestas a las del tradicional árbol cósmico o "árbol de la vida", pero mantiene el carácter dual: vida y muerte, es decir, de nuevo el símbolo mesiánico de la cruz, del martirio. 
Sin embargo, como consecuencia del efecto especular del proceder del Bueno, estos personajes cambian también de comportamiento como si la conciencia hubiera despertado en ellos. Ahora, el maestro Pietrochiodo intenta construir una máquina "buena" encargada por el Bueno y que sirva para muchas cosas. Por su parte, el doctor Trelawney (intuyendo que tendrá que ser él quien una a las dos partes del vizconde) se dedica a la lectura de tratados de anatomía humana y reanuda la práctica de la medicina para aliviar los males de la gente, a la manera del vizconde.

"Lo bueno" y " lo malo", la división de la sociedad y lo sustancial del ser humano, que se compone de parte de luz positiva y de parte de sombra, de maldad, de pecado, están representados también en dos grupos contrapuestos.

c) Los leprosos son gente marginada por su enfermedad y, por tanto, están condenados a vivir aparte en una aldea llamada Pratofungo donde la vida es un perpetuo jolgorio. Representan el hedonismo, la alegría de vivir, la decadencia feliz, la irresponsabilidad etc.

d) Los hugonotes 22 de Col Gerbido, huídos de Francia por sus ideas religiosas, ilustran la división opuesta, representan la moral, el trabajo duro, etc. evocan una ética religiosa sin religión; representan la desesperanza, sentimiento que el autor pone de manifiesto, entre otras formas con la enumeración cerrada de la siguiente descripción:

"Avevano perduto i loro libri e i loro oggetti sacri, e ora non avevano più né Bibbia da leggere, né messa da dire, né inni da cantare, né preghiere da recitare" (p. 42).

e) Pamela, la pastorcilla, dentro de este mundo de buenos y malos presentado por Calvino ${ }^{23}$, es un ideograma esquemático de un carácter concreto de mujer que representa el contrapunto humano de un personaje sin humanidad, como es el demediado vizconde. Supone, además, otra forma de desdoblamiento, de tensión y sufrimiento, ya que ella ama a cada una de las dos mitades y es fiel a cada una de ellas.

21. La enumeración abierta de los distintos objetos recalca el absurdo interés del doctor por los fuegos fatuos.

22. La imagen de los hugonotes, seguidores de Calvino, se justifica según el autor, entre otras razones, por una especie de esoterismo familiar, tratando de explicar el origen hipotético de su nombre.

El pensamiento de Calvino sostenía:

a) la soberanía absoluta y transcendente de Dios.

b) el estado de pecado heredado por todos los hombres y la imposibilidad en que éstos se hallan de realizar nada grato a Dios a causa de la maldición del pecado original con que Adán corrompió a toda la raza humana.

c) la condenación eterna, merecida en consecuencia por todos los hombres que carecen de mérito o de poder para evitarla.

Estas ideas, que recalcaban la idea de Dios, implicaban una sociedad relativamente igualitaria y un estricto código moral.

23. CALVINO, I., en Magazine Littéraire, n² 274, Février, 1990, p. 36. 
El juego de contrastes, repetido a lo largo del relato, se manifiesta ahora con Pamela en una inversión de valores 24 : lo que es inferior toma el lugar de lo superior, y así los animales ocupan y duermen en la casa, mientras que Pamela y sus padres lo hacen fuera de la misma, ya sea en el pajar, en una barrica o en una hamaca, entre el olivo y la higuera. Después, ella se irá a vivir al bosque entre dos pinos, con una cabra y un pato. En cualquier caso, el espacio doméstico es considerado como un espacio liliputiense en el que reinan los diferentes animales frente a los humanos.

La dualidad y la antítesis se manifiestan igualmente en la simbología de elementos como el pino y el olivo; el primero, de carácter masculino, y de carácter femenino el segundo, si bien la presencia del olivo puede interpretarse tambien como una imagen del compromiso: significa paz y humildad.

Además de alegre y desenfadada, Pamela es también una mujer inteligente, pues, cuando a la población llegan noticias de la doble naturaleza del vizconde, ella es la primera en advertir la presencia de la mitad buena, como la parte que faltaba al otro, es decir, de sintetizar al hombre.

“Che voi siete un po'buono e un po'cattivo. Adesso tutto è naturale” (p. 72)

Muy pronto Pamela piensa que la mitad buena está chalada, y que tampoco le gustan los tipos así, pues ambos son extremos de un mismo ser, pero ella sigue el juego a los dos y promete casarse con ambos. Con motivo de la boda, se establece un curioso juego de mensajes y hechos encadenados entre los distintos personajes. Cuando no existe más que el Doliente:

- Pamela dice a sus padres que, si el vizconde va a visitarles, le echen encima las abejas y le aten sobre el hormiguero.

- El vizconde llega y los padres le cuentan las intenciones de su hija, éste quema el pajar y la barrica, les ata y les amordaza.

- Pamela regresa a casa y se encuentra a sus padres atados y amordazados, uno en la colmena, otro en el hormiguero.

Al día siguiente:

-Los padres atan a Pamela y la encierran con los animales. -Pamela, que sabe hablar con los animales, logra que éstos la salven y se va a vivir al bosque.

Más adelante, las dos partes de Medardo, "que vagan atormentadas por ansias opuestas", toman una decisión:

- Por un lado, el Doliente dice a la madre de Pamela que tiene que casarse con el Bueno y que no le pida explicaciones.

- El Bueno dice al padre de Pamela que su hija se case con el Doliente y que, si así les devuelve la paz, él se irá de Terralba.

24. Esta estructura pertenece al régimen místico de la imagen, la de la concentración. Cf. DURAND, G., Les structures anthropologiques de l'imaginaire, Bordas, Paris, 1973. (pp. 317-320). 
- La madre dice a Pamela que se case con el Bueno.

- El padre dice a Pamela que se case con el Doliente en la iglesia.

- Pamela promete al Doliente casarse con él y promete también al Bueno casarse con él.

Pamela, expectante hasta el último momento, por no saber con cuál de las mitades se casará, finalmente lo hace con el Bueno, ya que el Doliente llega con retraso a la ceremonia a causa de un accidente de su caballo. Este, sin embargo, reclamará para sí la identidad de Medardo de Terralba y, por tanto, a la mujer que se ha casado con él.

\section{La antítesis del discurso y otros recursos narrativos}

\section{a. La antítesis.}

Sabemos que todo conflicto opone dos términos y que la noción misma de conflicto está directamente relacionada con la antítesis. Como ya hemos visto en la obra, las antítesis son innumerables, precisamente como manifestación del conflicto interno del personaje demediado, esquizoide, que adopta una actitud conflictiva entre él mismo y el mundo; actitud que se manifiesta, sobre todo, en el plano de la representación, al presentar las imágenes por parejas en una especie de simetría invertida. Todas las representaciones, todos los actos, son considerados desde el punto de vista de la antítesis "bien" versus "mal".

La oposición aparece a lo largo de todo el relato, no sólo como recurso narrativo, sino también como una estructura que va tejiendo los distintos episodios y personajes. Unos y otros son efectos especulares de la visión dualista del mundo (bien/mal, vida/muerte, luz/sombra, alegría/sufrimiento, amor/odio, alto/bajo, etc.) y demediada del personaje.

Una de las antítesis más significativas es la del conflicto ${ }^{25}$ que se establece entre las dos personalidades al final de la obra con motivo de la boda, y que se traduce en una imagen de hostilidad del personaje consigo mismo (las dos partes se retan en un duelo a muerte), el combate del personaje positivo, de luz contra su yo negativo, su parte oscura, maravillosamente presentado en una escena acompañada de numerosos elementos simbólicos que ilustran el destino del ser dividido que aspira a una unidad imposible:

25. Vid. VON FRANZ, M.L., L’ombre et le mal dans les contes des fées, La Fontaine de Pierre, Paris, 1980. quien opina que es preferible negociar con "la sombra" en lugar de entablar con ella un combate que no lleve a ninguna parte, porque, si la sombra se integra, es portadora de fuerzas nuevas para el ser. Sin embargo, esta actitud no se plantea en ningún momento de la obra. 
"C'era l'alba verdastra; sul prato i due sottili duellanti neri erano fermi con le spade sull'attenti. Il lebbroso soffiò il corno: era il segnale; il cielo vibrò come una membrana tesa, i ghiri nelle tane affondarono le unghie nel terricio, le gazze senza togliere il capo di sotto l'ala si strapparono una penna dall'ascella facendosi dolore, e la bocca del lombrico mangiò la propria coda, e la vipera si punse coi suoi denti, e la vespa si ruppe l'aculeo sulla pietra, e ogni cosa si voltava contro se stessa, la brina delle pozze ghiacciava, i licheni diventavano pietra e le pietre lichene, la foglia secca diventava terra, e la gomma spessa e dura uccideva senza scampo gli alberi. Così l'uomo s'avventava contro di sé, con entrambe le mani armate d'una spada" (p. 98).

\section{b. La dualidad, el número dos, la mitad.}

Aunque cuantitativamente el $\operatorname{dos}^{26}$ es el doble de la unidad, cualitativamente el dos no es más que una de sus mitades, el dos expresa la dualidad, la polaridad, la división de la unidad. Tanto el número dos como la mitad son elementos presentes a lo largo de la obra que redundan en el carácter dual de la misma.

Al llegar a Terralba, Medardo paga a los portadores la mitad de la suma pactada. Después, a la muerte de su padre, va a dejarlo todo a su imagen y semejanza: peras cortadas por la mitad (quedaba sólo la derecha), media rana, medio melón, hongos venenosos y comestibles cortados por la mitad, robellones con medio tallo y media sombrilla...

Las primeras víctimas del patíbulo son veinte personas y diez gatos, es decir, la mitad; otra serie de víctimas la constituyen campesinos que habían discutido con el vizconde por haber doblado sus tributos.

El modo de hacer saber a Pamela su interés por ella es también el de partir las cosas por la mitad: las margaritas tenían la mitad de los pétalos, lo mismo que las chirivías y los vilanos con sólo media esfera.

Este recurso está igualmente relacionado con la bimembración morfológica y sintáctica. Citamos a modo de ejemplo: "Li vide, i turchi. Ne arrivavano due propio di lì.. Uno dei due turchi morì e altro uccise un altro" (p. 14); dos artilleros turcos que parecían dos astrónomos; dos carros recogían los cuerpos; dos selecciones, la primera en el campo de batalla: muertos y heridos; la segunda en el hospital: pacientes vivos y pacientes muertos...

26. El no 2 es el número del dualismo. Según SERINGUE, Ph., Les symboles, Helios, Génève, 1988. “Chacun de nous recèle un dualisme, qu'il s'agisse de la vie intérieure et de la vie extérieure, de l'esprit et de la matière, de l'âme et du corps, des germes de vie et de mort, des tendances au bien et au mal...L'ambivalence peut aller jusqu'à un antagonisme: le nombre 2 devient parfois un symbole de conflit...Le deux symbolise aussi les deux natures, humaine et divine de Jésus-Christ". 


\section{c. Otros procedimientos formales}

En Seis propuestas para el próximo milenio, Calvino define su concepto de exactitud en la literatura, entre otras cosas, como la evocación de imágenes nítidas, incisivas, memorables. Expresa también su predilección por las formas geométricas, por las simetrías, por la combinatoria, por las proporciones numéricas.

En Il visconte dimezzato, el autor utiliza estos recursos narrativos y también una serie de mensajes ${ }^{27}$ superpuestos a modo de jeroglíficos, seriados de tres en tres. Aparecen, en primer lugar, los mensajes en clave dejados por el Demediado a Pamela.

1er mensaje: Restos de la mitad de un murciélago y la mitad de una medusa, encontrados en el lugar donde Pamela suele sentarse habitualmente. Este mensaje que ella comprende inmediatamente lo interpreta como: Cita esta noche a la orilla del mar.

$2^{\circ}$ mensaje: Pamela percibe gemidos y aleteos de un gallo atado por las alas en una rama de morera, y gruesas y peludas orugas devorándolo junto con un nido de procesionarias e insectos dañinos y que interpreta así: Mañana de madrugada nos veremos en el bosque.

$3^{\circ}$ mensaje: Aparece un cadáver ensangrentado de media ardilla cortada a lo largo en su regazo pero con la leonada cola intacta. La interpretación posible: El vizconde respetará lo que Pamela tiene de bueno y de hermoso si acepta ir con él al castillo.

La segunda serie de lo que el autor llama "signos de comunicación" están relacionados con Medardo el Bueno. Este también va dejando señales para avisar al Dr. Trelawney en sus visitas a los enfermos, viejos, pobres, etc..

$1^{\circ}$ ) El granado del huerto de Bacciccia tenía cada una de las frutas maduras anudada con un pañuelo. Interpretación:

a) Dolor de muelas del propietario

b) Protección de las granadas.

c) Aviso al Dr. Trelawney para que visitara al enfermo y llevara las tenazas.

$2^{\circ}$ ) Tres gallinas atadas a la barandilla y descargando estiércol sobre un girasol del prior Cecco. Interpretación:

a) El prior debía tener cagalera.

b) Las gallinas abonan el girasol.

c) Aviso de la urgencia del caso.

$3^{\circ}$ ) Fila de caracoles comestibles en la escalera de la vieja Giromina. Interpretación:

a) Regalo del vizconde a Giromina.

b) Empeoramiento de la enfermedad del corazón de la pobre vieja.

c) Aviso para que el doctor entrara despacio en casa para no asustarla.

27. Tanto las estructuras paralelas y quiásticas ya citadas como los mensajes del Demediado y del Bueno a Pamela están vinculadas con la antítesis, aumentando el efecto estilístico y creando un determinado ritmo textual. 
La interposición del Doliente ante estos mismos hechos produce resultados totalmente antitéticos a los antes descritos. Así:

$\left.1^{\circ}\right)$ En el huerto de Bacciccia las granadas despachurradas en el suelo, y de las ramas colgaban los estribos de los pañuelos vacíos. - ¡Por piernas!

$2^{\circ}$ ) En el terrado del prior Cecco las gallinas estaban atadas al cañizo donde estaban puestos a secar los tomates, estropeando éstos. - ¡Por piernas!

$3^{\circ}$ ) Ante la casa de Giromina y en la escalera había caracoles aplastados, todo babas y trozos de concha. -iPor piernas!

Encontramos igualmente la antítesis ante otros hechos que nos hablan de la doble naturaleza de Medardo:

- Niños extraviados en el bosque eran encontrados por el vizconde, que los devolvía a sus casas de la mano y les regalaba higos y buñuelos/ niños raptados eran encontrados luego prisioneros en grutas obstruidas con piedras.

- Pobres viudas eran ayudadas por él a transportar haces /derrumbamientos de troncos y rocas caían sobre las viejecitas.

- Arboles frutales desarraigados por el viento eran enderezados y afianzados en sus terrones antes de que los propietarios hubieran sacado la nariz por la puerta/calabazas recién maduras eran hechas pedazos por puro espíritu malvado.

Las diferentes situaciones citadas que cobran forma y sentido a través de la escritura, suponen un punto de confluencia entre la realidad y la fantasía y manifiestan otro de los valores de Calvino en la literatura, el de la visibilidad 28 .

\section{Conclusión}

A lo largo del estudio hemos tratado de dibujar el perfil del personaje principal, un personaje que se escinde en dos, lo que genera un desdoblamiento de la personalidad y un ser incompleto, física y psíquicamente, en cada una de sus dos mitades.

Esta escisión se hace sentir en el relato a través del uso continuo de la antítesis, como hemos mostrado en numerosos ejemplos. Por otra parte, hemos aludido al simbolismo de las imágenes iniciales que metaforizan el estado del mundo como algo incompleto, de manera que el protagonista sería una reduplicación microcósmica de la dualidad del universo: bien y mal; principio y fin; armonía y caos. Por este efecto especular tanto los personajes como el mundo de Medardo son duplicaciones "ad infinitum" de la dualidad antitética que, como principio organizador, configura toda la obra.

28. Vid. CALVINO, I., Seis propuestas para el próximo milenio, Siruela, S.A., Madrid, 1994, pp. 97-113. 
Al igual que a D. Philippe, ${ }^{29}$ nos parece que en este relato fantástico y visionario, el autor ha jugado con la polisemia del texto, lo que conduce claramente a su ambigüedad, entendiendo como tal la complejidad del contenido semántico. En este sentido, no estamos de acuerdo con el autor cuando elogia lo demediado, tanto a través de las reflexiones de El Doliente,

"Così si potese dimezzare ogni cosa intera, così ognuno potesse uscire dalla sua ottusa e ignorante interezza. Ero intero e tutte le cose erano per me naturali e confuse, stupide come l'aria; credevo di veder tutto e non era che la scorza. Se mai tu diventerai metà di te stesso, e te l'auguro, ragazzo, capirai cose al di là della comune intelligenza dei cervelli interi. Avrai perso metà di te e del mondo, ma la metà rimasta sarà mille volte più profonda e preziosa. E tu pure vorrai che tutto sia dimezzato e straziato a tua immagine, perché bellezza e sapienza e giustizia ci sono solo in ciò che è fatto a brani” (p. 51)

como a través del Bueno, que también opina de la misma manera :

"O Pamela, questo è il bene dell'essere dimezzato: il capire d'ogni persona e cosa al mondo la pena che ognuno e ognuna ha per la propria incompletezza. Io ero intero e non capivo, e mi muovevo sordo e incomunicabile tra i dolori e le ferite seminati dovunque, là dove meno da intero uno osa credere. Non io solo, Pamela, sono un essere spaccato e divelto, ma tu pure e tutti. Ecco ora io ho una fraternità che prima, da intero, non conoscevo: quella con tutte le mutilazioni e le mancanze del mondo" (p. 74).

La intención del autor es, según sus propias palabras, la de combatir todas las divisiones del hombre, la de augurar el hombre pleno, la de aspirar a la completez por encima de todas las mutilaciones metafóricas que la sociedad impone. Nosotros pensamos que la armonía se encuentra no en el demediamiento, sino en el ser completo que resulta tras la experiencia desgraciada. Sin embargo, el texto no nos da pie para saber lo que ocurre posteriormente con el personaje unido por el doctor Trelawney, después de curar las respectivas heridas abiertas en el duelo a muerte. Sólo sabemos que Medardo de Terralba

"Ritornò uomo intero, né cattivo né buono, un miscuglio di cattiveria e bontà, cioè apparentemente non dissimile da quello ch'era prima di esser dimezzato" (p. 100).

29. PHILIPPE, D., Les parcours d'écriture en Magazine Littéraire p. 30.

"L'imaginaire fondateur des fictions calviniennes a alors pour but de déclencher à cause de son irréalisme même, la mise en marche d'un mécanisme interprétatif dédoublant les niveaux de réalité, introduisant, à tous les sens du mot, un jeu dans le texte". 
Quizá, la explicación lógica se pueda encontrar en el segundo relato de la trilogía Nuestros antepasados, donde el protagonista asume un único papel y lo mantiene hasta el fin de su vida. En este sentido, se puede hablar de una obra incompleta, ya que parece ser la expresión de uno de los momentos integrantes en la dialéctica inherente a la vida humana, posiblemente el momento más importante de la misma: el de la disociación de los contrarios, disociación que genera la tensión productora de la fuerza y la energía que el ser humano requiere para superar e integrar tal disociación en una realidad más rica.

Como hemos apuntado, no parece que sea la disociación el estado ideal, más aún, podemos decir que no constituye "estado" alguno, ya que no es posible "instalarse en ella, porque lo que justamente lo caracteriza es la contradicción, la crisis, la "inquietud", es decir, lo contrario de lo que es propio de un "estado". Sin embargo, sí que es un momento necesario para la construcción de "estado" (ahora sí) que contenga los polos opuestos en una unidad que los integre. Este "estado" nuevamente deberá entrar en crisis para ir, de este modo, conquistando nuevas y más ricas posibilidades de ser, que se encuentran en el ser humano esperando a ser actualizadas. 